\title{
REFRIGERATION AND AIR CONDITIONING USING ALCOHOL AS A REFRIGERANT
}

\author{
Umang Srivastava ${ }^{1}$, Anand Singh ${ }^{2}$, Shariq Raza ${ }^{3}$, Abhishek Kumar ${ }^{4}$ \\ ${ }^{1}$ B.Tech, Mechanical Engineering, United College of Engineering and Management, U.P., India \\ ${ }^{2}$ B.Tech, Mechanical Engineering, United College of Engineering and Management, U.P., India \\ ${ }^{3}$ B.Tech, Mechanical Engineering, United College of Engineering and Management, U.P., India \\ ${ }^{4}$ B.Tech, Mechanical Engineering, United College of Engineering and Management, U.P., India
}

\begin{abstract}
In our daily life, refrigeration and air conditioning plays a very vital role. We cannot imagine our life in absence of these facilities. These facilities are very much helpful to us but on other hand they are equally dangerous for our environment and its future. The use of harmful refrigerants such as CFC's are rapidly degrading the ozone layer and causing the Global warming, which is a major concern for this initiation in the field of refrigerants. Thus we are replacing the refrigerants with the ecofriendly alternate that is Alcohol. We are making a new process by combining some aspects of two processes which already exits namely Vapours Compression Refrigeration System AndVapour Absorption Refrigeration System.
\end{abstract}

Keywords: - Qin= Heat Input; Qout= Heat output; PC=Phase Changer; COP= Coefficient of performance; $\eta=$ Efficiency, VARS etc...

\section{INTRODUCTION}

Now a days refrigerators and air conditioners are used which are able to make chilly atmosphere and icy water in a convincing manner. They help us to live in a soothing ambience; they maintain the humidity and freshness, inside the room. Whereas the refrigerator is one of the major parts of one's life as they enable us to keep our eatables in a secure zone which is totally protected from that of bacteria, fungi, and other microbial attacks. The refrigeration process works on the Reverse Brayton cycle. These cycles includes the processes which are: compression, expansion, evaporation. For which they utilizes the compressor, in which the harmful refrigerants are filled, which on leaking causes many hazards to nature. Among which one of the major is GLOBAL WARMING. According to the current refrigeration cycle the compressor compresses the refrigerant at 500psi, these compressed gases is sent to the condensers, where it gets condensed and the phase changes from gas to liquid. This high pressurized liquid is sent for expansion in expansion valve, where its pressure decreases suddenly causing in sudden temperature drop. This cold liquid is sent to the evaporator, where it absorbs the atmospheric heat and gets converted into vapour phase again. This vapor is the sucked in by the compressor and thus the cycle completes (Fig1). So our main concern is to replace the harmful refrigerants and minimize the power consumption through compression work. Hence we are combining few cycles and their phenomenon to achieve our goal of using alcohol as a refrigerant. In our cycle we are replacing the compressor with the pumps. A concept of phase changer is used in our system, evaporators, condensers and expansion valves are same, with slight changes in their dimensions. Also we can take into account the ultimate non-conventional source of energy, solar energy.

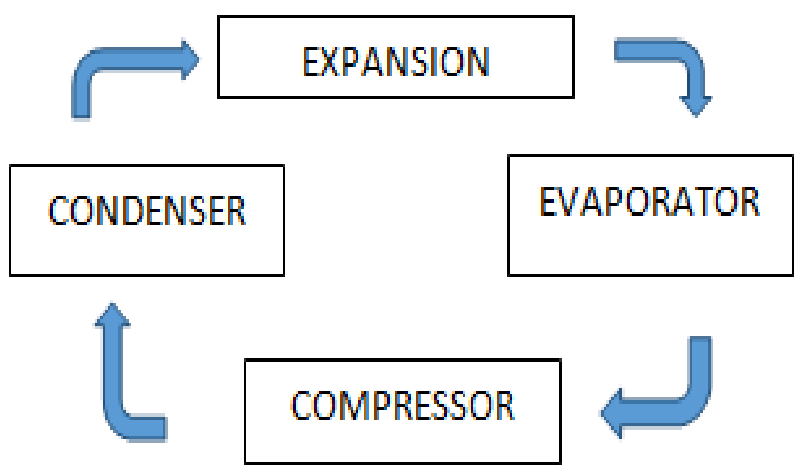

Fig 1: Vapour compression refrigeration system

\section{MAJOR COMPONENTS}

Inthis cycle certain changes with the componets are made which are as follows:

\subsection{Phase Changer}

As the name suggests, a Phase changer (Fig.2) is device in which the phase of alcohol is changed from liquid to gaseous form.

In this system, a closed tank is used to make a chamber for hot water, there is a copper pipe coming from the pump, enters the chamber in coiled structure, providing more area and time to alcohol to change its phase, as alcohol 
(ETHANOL) vaporizes at $78^{\circ} \mathrm{C}$, thus we need to maintain temperature of the chamber around $100^{\circ} \mathrm{C}$, for proper phase change.

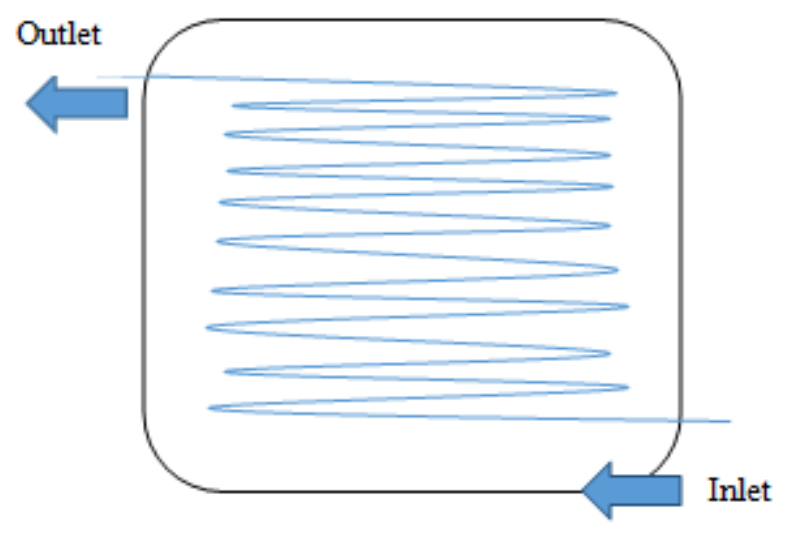

Fig 2: Showing the Schematic diagram of Phase changer.

\subsection{Pyramid Shaped Condenser}

The concept of pyramid shaped condenser is used because of its shape, in this condenser the inner walls of the condenser will be attached with the protruding needle like structures. So that the surface area of the vaporized alcohol should be enhanced, this will work as baffles with very small surface, causing the alcohol to spend more time in that needles, these needles will provide greater convective heat transfer into the surrounding, thus causing condensation of alcohol and transforming it into liquid phase. This liquid alcohol is now get collected into the tank.

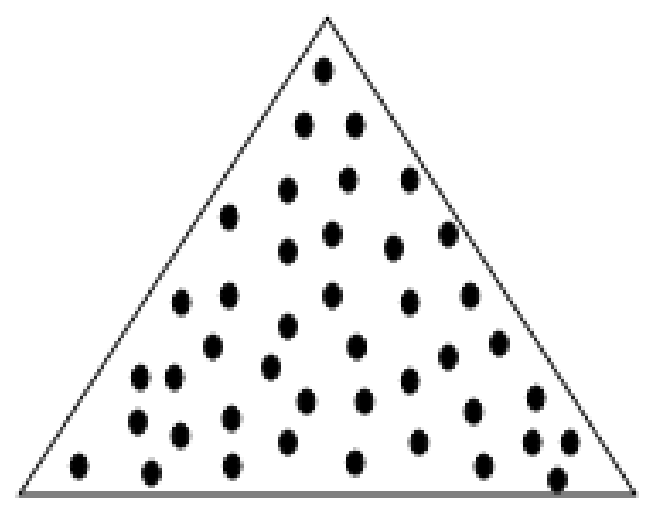

Fig 3: Inner front view of pyramid condenser

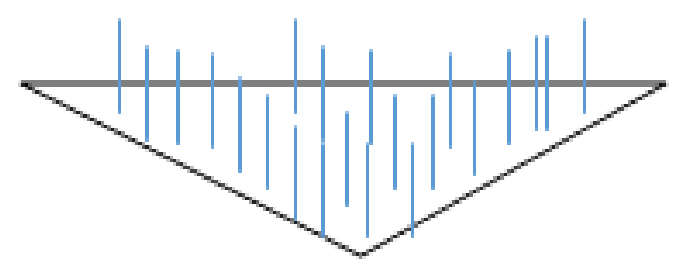

Fig 4: Inner top view of pyramid condenser

\section{CYCLE DESCRIPTION}

Fig. 2 Shows the cycle, in this system there is a replacement of compressor with that of pump. The concept of phase changer (PC) is introduced; also one new type of condenser will be installed just after the evaporator in which protruding needle like structures will be fixed to the inner wall of pyramid shaped condenser. There is a tank for the storage of Alcohol, and the rest of the components such as the expansion valve, evaporator and the condenser are similar. As the cycle starts the Pump Create suction and suck in the Alcohol, this alcohol is then transferred to the phase changer here the liquid alcohol is changed into the vapour state by consuming the surrounding heat, after this the vaporized alcohol is sent to the condenser, where the change of phase take place again and alcohol gets converted into the liquid form again with high pressure in output. This high pressured alcohol is passed through the expansion valve, Where the drastic temperature drop takes place and pressure is decreased due to temperature drop. Now this liquid alcohol is sent to the Evaporator, as its temperature is very low so it easily absorbs the heat from the surrounding atmosphere thus giving the refrigerating effect.

Now when the temperature of the liquid alcohol is raised, after absorbing the heat it gets converted into the vapour phase again. This vaporized alcohol is sent to the Pyramid like condenser, which contains the protruding needle like structure, acting like baffles, so that the area of surface must increase, for the vaporized alcohol to condense again with process of natural convection.

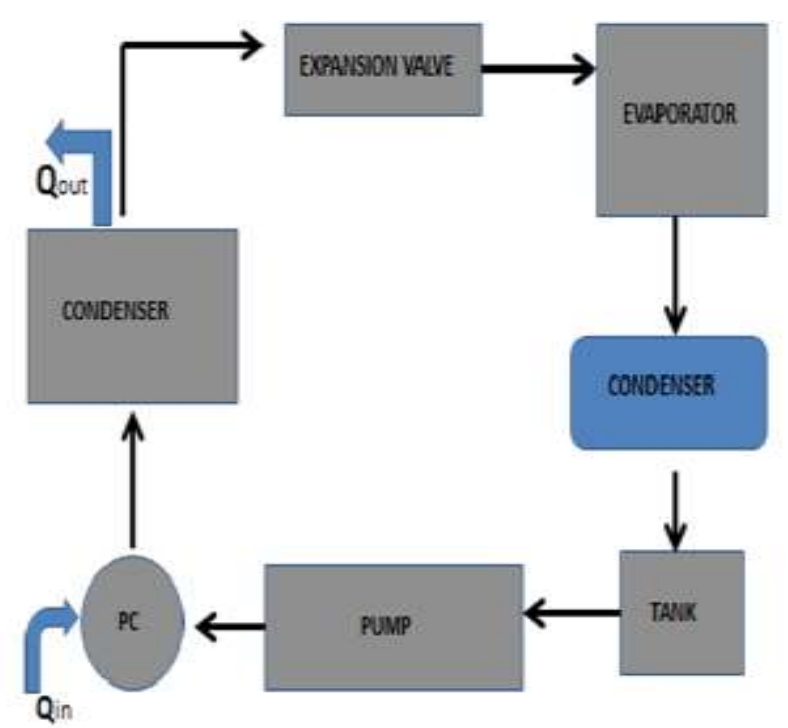

Fig -5: Showing the process of refrigeration

Now the Alcohol here enters and condenses back to the liquid phase, which is then collected back to storage tank. This completes the cycle. 


\section{PROPERTIES OF REFRIGERANT (Ethanol)}

- $\quad$ Boiling Point: $78^{\circ} \mathrm{C}$

- Freezing Point: $-114.14^{\circ} \mathrm{C}$

- Specific Heat: $112.4 \mathrm{~J} / \mathrm{mol} \mathrm{k}$

- Density: $0.7893 \mathrm{~g} / \mathrm{cm}^{3}$ (At $20^{\circ} \mathrm{C}$ )

- Viscosity: $1.2 \mathrm{mPa} . \mathrm{sec}$

- Enthalpy of Vaporization: $42.3 \mathrm{~kJ} / \mathrm{mol}$

- Vapour Pressure: $5.95 \mathrm{kPa}\left(\right.$ At $20^{\circ} \mathrm{C}$ )

- Triple point: $-123^{\circ} \mathrm{C}$ (At pressure $0.00043 \mathrm{~Pa}$ )

- Critical Temperature: $241^{\circ} \mathrm{C}$ At 63 bar

- Thermal Conductivity: $0.171 \mathrm{watt} / \mathrm{mK}$ at $27^{\circ} \mathrm{C}$

- Latent heat of vaporization: $846 \mathrm{~kJ} / \mathrm{kg}$

\section{Applications}

- This system can be used in automobiles

- Cold storages

- House hold refrigerators

- Domestic as well as commercial air conditioning

- In large production industries

\section{CONCLUSION}

After testing the setup, we come to a conclusion that the system can be proved efficient for the domestic and industrial applications. The use of this system can be done in the power plants as the high temperature water can be supplied from the economizer, also the flue gases in the chimney can be circulated to increase the temperature of the phase changer.

\section{REFERENCES}

[1] KutubUddin, Takahiko Miyazaki, Thermodynamic Analysis of HFCS- Ethanol Sub cooler type hybrid refrigeration.

[2] ShrenikkumarOswal, HemantJagtap, Factors affecting thermal performance of fins and analysis of fins with ANSYS Icepak (June 2015)

[3] Prof. U.S.P. Shet, Prof. T. Sundarajan and Prof. J.M. Malikarjuna, Air refrigeration System and Bell colemann Cycle, indian Institute of Technology Madras

[4] Dilip Kumar Mohanty, AbhijeetPadhiary, Thermodynamic performance analysis of a solar vapour absorption refrigeration system.

\section{BIOGRAPHIES}

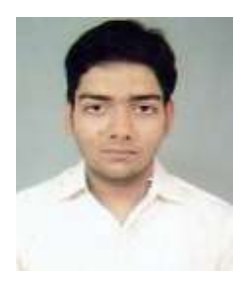

I am Umang Srivastava, Mechanical Engineer, B.tech from United group of Institutions. My interest is in HVAC and AUTOMOBILES.

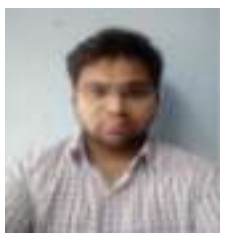

I am Shariq Raza, Mechanical Engineer, B.Tech from United group of Institutions. My interest is in FLUID MECHANICS and MACHINERY

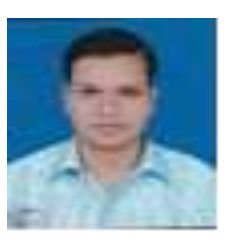

I am Abhishek Kumar , Mechanical Engineer from OBRA, Sonebhadra, My interest is in Environmental Science And its Conservation.

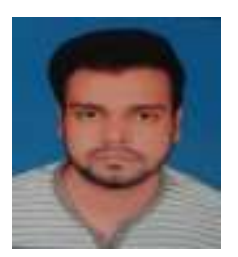

I am Anand Singh, Mechanical Engineer, I was born In Mirzapur. My Interest is in SOM and DOM. 